\title{
Qualidade de vida no trabalho e saúde/doença
}

\author{
Quality working life and health/illness
}

Francisco Antônio de Castro Lacaz 1

\begin{abstract}
Using as starting point the discussion of many concepts of the term Quality Working Life (QWL) is assumed the idea of priority to changes in working organization and worker's participation, like pointed out the International Program on Bettering Working Conditions and Labor Environment, proposed by International Labor Organization (ILO), in 1976. Are pointed the limits of $Q W L$ in a reality like the Brazilian, where democracy in working places is still so fragile. Besides, vis-à-vis Taylorism/ Fordism, are discussed the changes in the organization of working process that occur in the QWL within the process of job redesign, pointing the necessity to think about epidemiological indicators that show the relationships health/ ilness and the new ways of management and organization of the productive process, represented by the working related diseases, whose nexus with working process has a more complex causality.
\end{abstract}

Key words Quality; Working Process; Workers; Health/Disease Process
Resumo A partir da discussão das noções que assumiu a Qualidade de Vida no Trabalho (QVT), priorizou-se a que valoriza as mudanças na organização do trabalho, a participação dos trabalhadores, conforme o Programa Internacional para o Melhoramento das Condições e dos Ambientes de Trabalho (PIACT), da Organização Internacional do Trabalho (OIT), 1976. Diante da escolha, são apontados os limites da QVT na nossa realidade, em que a democracia nos locais de trabalho é ainda frágil. Ao lado disso, vis à vis o taylorismo/fordismo, discute-se as mudanças na organização do processo de trabalho que acompanham a QVT na reestruturação produtiva, apontando para a necessidade de pensar-se indicadores epidemiológicos que expressem as relações saúdeldoença e as novas formas de gestão, divisão e organização da produção, representadas pelas doenças relacionadas ao trabalho, cujo nexo com ele têm causalidade mais complexa.

Palavras-chave Qualidade; Processo de trabalho; Participação; Saúde/Doença

\footnotetext{
1 Centro de Estudos em Saúde Coletiva (Cesco), Universidade Federal de São Paulo, Escola Paulista de Medicina, Rua dos Otonis, 592, 04025-001 São Paulo, SP.
} 


\section{Introdução}

Qualidade de Vida no Trabalho (QVT) é uma terminologia que tem sido largamente difundida nos últimos anos, inclusive no Brasil. Como incorpora uma imprecisão conceitual, vem dando margem a uma série de práticas nela contidas que ora aproximam-se da qualidade de processo e de produto, ora com esta se confundem. $\mathrm{O}$ conceito, através dos programas de qualidade total, vem impregnando propostas de práticas empresariais (Rodrigues, 1991).

Se sua origem pode ser encontrada no longínquo pós-guerra, como conseqüência da implantação do Plano Marshall para a reconstrução da Europa (Vieira, 1993), sua trajetória tem passado por vários enfoques. Uns enfatizam aspectos da reação individual do trabalhador às experiências de trabalho (década de 1960); outros, aspectos de melhoria das condições e ambientes de trabalho, visando maior satisfação e produtividade (década de 1970) (Rodrigues, 1991). Articulada a esta última abordagem, a QVT também é vista como um movimento, no qual termos como gerenciamento participativo e democracia industrial são adotados freqüentemente, como seus ideais (meados da década de 1970). Por fim, nos anos 80, adquire importância como um conceito globalizante, na busca de enfrentar as questões ligadas à produtividade e à qualidade total (Zavattaro, 1999).

Observa-se, assim, que a QVT dialoga com noções como motivação, satisfação, saúde-segurança no trabalho, envolvendo discussões mais recentes sobre novas formas de organização do trabalho e novas tecnologias (Sato, 1999).

Aqui, interessa discutir a vertente que prioriza as condições, ambientes, organização do trabalho e as tecnologias. Vertente esta, advogada pela Organização Internacional do Trabalho (OIT) a partir de 1976, quando lança e fomenta o desenvolvimento do Programa Internacional para o Melhoramento das Condições e dos Ambientes de Trabalho (PIACT). Trata-se de uma proposta que procura articular duas tendências: uma dirigida ao melhoramento da qualidade geral de vida como uma aspiração básica para a humanidade hoje e que não pode sofrer solução de continuidade no portão da fábrica. (...); a outra, concernente a uma maior participação dos trabalhadores nas decisões que diretamente dizem respeito à sua vida profissional (Mendes, 1988a).
Surgida na esteira da cada vez maior mobilização dos trabalhadores europeus pela ampliação de seus direitos no trabalho, que ocorre no final dos anos 60 e início dos 70, a proposta do PIACT incorpora tais demandas (Parmegianni, 1986). Reflexo disso, na década de 1980, consolida-se uma tendência que baseia a QVT na maior participação do trabalhador na empresa, na perspectiva de tornar o trabalho mais humanizado. Agora os trabalhadores são vistos como sujeitos, estando sua realização calcada no desenvolvimento e aprofundamento de suas potencialidades.

Assim, busca-se superar a etapa da prevenção dos acidentes e doenças tidos como diretamente relacionados ao trabalho, para avançar na discussão dos agravos relacionados ao trabalho. Conforme proposição do National Institute of Occupational Safety and Health (NIOSH), passam a incorporar grupos de doenças e acidentes que também ocorrem na população geral, mas que em determinadas categorias de trabalhadores adquirem um perfil patológico diferenciado (Quadro 1).

Expressão dessas preocupações, o PIACT já propunha uma estratégia de intervenção sobre o processo de trabalho, ou seja, ... a carga de trabalho, a duração da jornada, (...), a organização e o conteúdo do trabalho e a escolha da tecnologia (Mendes, 1988).

Do que foi até aqui exposto, observa-se que se trata de um discurso que remete, num extremo, a mudanças na organização do processo de trabalho como conseqüência do movimento de qualidade do trabalho e/ou da democracia industrial adotada nos países escandinavos no início da década de 1970 (Ortsman, 1984). No extremo oposto, lida com práticas que se preocupam muito pouco com as condições e organização do trabalho, na medida que sua vertente individualista apenas incentiva a prática de hábitos de vida saudáveis (Sato, 1999). Se, em princípio, não se pode banir tais iniciativas, é mister apontar que elas não atingem as relações e a organização do processo de trabalho, categoria esta central para explicar os principais problemas atuais de saúde dos trabalhadores.

Assim, a idéia de QVT procura amalgamar interesses diversos e contraditórios, presentes nos ambientes e condições de trabalho, em empresas públicas ou privadas. Interesses estes que não se resumem aos do capital e do trabalho, mas também aos relativos ao mundo subjetivo (desejos, vivências, sentimentos), aos va- 
Quadro 1

Os dez principais grupos de doenças e acidentes relacionados com o trabalho, Estados Unidos, 1982.

1. Doenças pulmonares: asbestose, bissinose, silicose, pneumoconiose dos trabalhadores do carvão, câncer de pulmão, asma ocupacional.

2. Lesões músculo-esqueléticas: distúrbios da coluna lombar, do tronco, extremidades superiores, pescoço, extremidades inferiores, fenômeno de Raynaud traumaticamente induzido.

3. Cânceres ocupacionais (outros que não de pulmão): leucemia, mesotelioma, câncer de bexiga, de nariz e de fígado.

4. Amputações, fraturas, traumas oculares e politraumatismos.

5. Doenças cardiovasculares: hipertensão, coronariopatias e infarto agudo do miocárdio.

6. Distúrbios da reprodução: infertilidade, abortamento espontâneo, teratogênese.

7. Distúrbios neurotóxicos: neuropatias periféricas, encefalites tóxicas, psicoses, alterações de personalidade (relacionadas a exposições ocupacionais).

8. Perdas auditivas relacionadas com exposição a barulho excessivo.

9. Afecções dermatológicas: dermatoses, queimaduras térmicas e químicas, contusões.

10. Distúrbios da esfera psíquica: neuroses, distúrbios de personalidade, alcoolismo e dependência de drogas.

Fonte: National Institut of Occupational Safety and Health, 1983.

lores, crenças, ideologias e aos interesses econômicos e políticos (Sato, 1999). Ocorre, porém, que a possibilidade de abarcar-se tal gama de questões e demandas envolve uma rede e um mecanismo complexo de relações, em que o peso específico da atuação dos trabalhadores adquire papel fundamental. A propósito disso, Ciborra e Lanzara (1985), assessores de uma central sindical italiana, criticam a noção de qualidade de vida no trabalho e propõem a terminologia qualidade do trabalho mais adequada, na medida que procura incluir todas as características de uma certa atividade humana -, apontando que ela encerra uma concepção clínica, voltada à mudança de hábitos de vida e por isso atribuindo ao próprio trabalhador a responsabilidade de adaptar-se, de modo a otimizar sua qualidade de vida e de trabalho. Tal comportamento, não podemos esquecer, abre caminho para uma velha postura ideológica: a culpa da vítima pelo ato inseguro (Lacaz, 1983).

Observa-se, pois, que a idéia de QVT é complexa e mutante. Pressupõe tanto uma abordagem e um aporte informado pela saúde coletiva, como pela clínica; além de embutir uma descontextualização e despolitização das relações saúde-trabalho, tão marcantes no discurso sanitário.

No caso do Brasil, as políticas empresariais de programas de qualidade, conforme mostra
Heloani (1994), são caracterizadas por envolver mecanismos de controle da percepção e subjetividade para enquadrar trabalhadores mediante engrenagens que visam introjetar as normas e metas da empresa.

Do lado dos trabalhadores, considerandose a história recente do movimento sindical, do então chamado novo sindicalismo, que data do final dos anos 70 e início dos 80, ver-seá que qualidade de vida (no trabalho) não foi uma bandeira de luta expressa, mas sim a melhoria das condições de trabalho e defesa da saúde como direito de cidadania (Ribeiro \& Lacaz, 1984). Não seria por isso mesmo que foi usada para contrapor-se ao discurso sobre a saúde defendido por parcela importante do movimento sindical de trabalhadores que, entre nós, sedimentou-se sobre uma plataforma claramente política para explicar a determinação do processo saúde/doença? (Rebouças et al., 1989).

\section{Qualidade de vida no trabalho: um conceito e prática instrumentais}

Para Ciborra \& Lanzara (1985), são várias as definições da expressão QVT, ora associandoa às características intrínsecas das tecnologias introduzidas e ao seu impacto; ora a elementos econômicos, como salário, incentivos, abo- 
nos, ou ainda a fatores ligados à saúde física, mental e à segurança e, em geral, ao bem-estar daqueles que trabalham. Em outros casos, segundo estes autores, considera-se que a QVT é determinada por fatores psicológicos, como grau de criatividade, de autonomia, de flexibilidade de que os trabalhadores podem desfrutar ou, (...) fatores organizativos e políticos, como a quantidade de controle pessoal sobre o posto de trabalho ou a quantidade de poder que os trabalhadores podem exercitar sobre o ambiente circundante a partir de seu posto de trabalho.

Mais ainda: do ponto de vista do planejamento do trabalho, a categoria qualidade do trabalho também apresenta nuanças problemáticas quando envolve questões abstratas, que desconsideram as relações concretas de produção no cotidiano do trabalho dos atores sociais. Assim, as questões conceituais sobre qualidade do trabalho consubstanciam-se, ainda conforme apontam Ciborra \& Lanzara (1985): De um lado por não parecer [em] ser definida [s] a partir de concepções explícitas que os atores da organização têm acerca de sua vida de trabalho, assume-se que a dimensão qualitativa do trabalho envolve relações econômicas entre os indivíduos e a empresa e, de outro, pelos problemas básicos de saúde e segurança do posto de trabalho.

Trata-se, então, em última instância, em concordância com Mendes e Dias (1991), de buscar a humanização do trabalho - um dos pressupostos do campo de práticas e saberes informado pelo encontro das formulações emanadas da Saúde Coletiva, da Medicina Social Latino-americana (Laurell, 1991) e da Saúde Pública, campo este denominado Saúde do Trabalhador (Lacaz, 1996).

Diante dessas assertivas, defende-se que dos elementos que explicitam a definição e a concretização da qualidade (de vida no) do trabalho, é o controle - que engloba a autonomia e o poder que os trabalhadores têm sobre os processos de trabalho, aí incluídas questões de saúde, segurança e suas relações com a organização do trabalho - um dos mais importantes que configuram ou determinam a qualidade de vida (no trabalho) das pessoas. E, frise-se, elas são o que são. Por isso, as condições, ambientes e organização do processo de trabalho devem respeitá-las em sua individualidade.

Aqui, a noção de controle deve ser entendida como a possibilidade dos trabalhadores conhecerem o que os incomoda, os fazem sofrer, adoecer, morrer e acidentar-se e articulada à viabilidade de interferir em tal realidade. Controlar as condições e a organização do trabalho implica, portanto, a possibilidade de serem sujeitos na situação. O exercício do controle tem tanto uma face objetiva (poder e familiaridade com o trabalho), como uma face subjetiva, ou seja, o limite que cada um suporta das exigências do trabalho (Sato, 1991).

Frise-se, ainda, que problemas afetos à temática da organização (divisão de tarefas, de homens, de tempo e de espaço) e do (re)planejamento do trabalho são também da maior relevância para que seja abordada de maneira produtiva e objetiva a discussão sobre qualidade do trabalho. E, aqui, é imperioso analisar como, de um lado, o controle e a disciplina fabris e, de outro, a gestão participativa como possibilidade de abertura de canais de negociação capital-trabalho, que levem à busca do encaminhamento das contradições e conflitos de interesses no trabalho, podem interferir no seu encaminhamento sob uma ótica coletiva. Assim, quando se fala de saúde e qualidade no trabalho, é sob este prisma que devem ser tratadas as questões a elas relacionadas. É, pois, equivocado basear a solução dos aspectos que interferem neste binômio em medidas de ordem individual como propõem os programas de qualidade difundidos pelas empresas, dada sua ineficácia e por serem questionáveis seus pressupostos, inclusive do ponto de vista bioético (Berlinguer, 1993). O que se propõe é, portanto, redirecionar o foco do debate e colocá-lo no âmbito das relações sociais de trabalho que se estabelecem no processo produtivo, para que fórmulas simplistas não sejam priorizadas quando se objetiva enfrentar a complexidade das questões que envolvem a temática aqui analisada.

Na perspectiva de ampliar o foco de luz sobre a temática, é esclarecedor atentar para o que observa Cattani (1997) no que diz respeito à autonomia, ao controle e ao poder dos trabalhadores $\mathrm{n}(\mathrm{d})$ o processo de trabalho.

$\mathrm{O}$ autor fala da antiga discussão do que representa a disciplina fabril sobre o tempo disponível e a vida dos operários com o advento da chamada Revolução Industrial na Europa Ocidental. Esta disciplina sofisticou-se com as mudanças introduzidas a partir das novas formas de organização do trabalho (Fleury e Vargas, 1983) que se consubstanciam hoje no que se denomina reestruturação produtiva, sempre visando a cada vez maior produtividade e a competitividade de mercado (Gorender, 1997). 
Assim, do simples relógio da fábrica, que regulava a hora de acordar e de dormir da família operária, ao cronômetro, base da intervenção racional sobre o trabalho construída e difundida por Taylor (1982), houve um disciplinamento e um assujeitamento (Foucault, 1994). Estes refinaram e aprofundaram a disciplina fabril, a qual ganhou cores mais vivas, constituindo-se nos pilares das propostas de organização e gestão do trabalho ainda sob o taylorismo e, posteriormente, sob o fordismo e mesmo sob o toyotismo (Antunes, 1995; Hirata e Zarifian, 1991).

Vários estudos epidemiológicos e qualitativos têm mostrado a importância da ausência de controle e autonomia dos trabalhadores sobre condições e organização do trabalho para explicar diversos problemas de saúde como os cardiovasculares, o sofrimento mental e mesmo os acidentes do trabalho (Gardell, 1982; Karasek, 1979; Karasek et al., 1981; Marmot e Theorell, 1988; Olsen e Kristensen, 1991; Seligmann-Silva, 1997; Vezina, 1998; Wünsch Filho, 1998). É isso que será discutido a seguir.

\section{Perfil patológico e qualidade $\mathbf{n}(\mathbf{d}) \mathbf{o}$ trabalho: as diferentes explicações}

Melhorar a qualidade das condições de saúde no trabalho, a partir do enfoque acima discutido, acarreta identificar os problemas em cada situação, com a participação efetiva dos sujeitos do processo de trabalho e replanejá-lo, o que envolve sempre um processo de negociação (Laurell \& Noriega, 1989). Não há apenas um modo racional de fazer o trabalho, mas diversos. Diante disso, não cabe somente aos gestores o papel de pensar e replanejar. Devem estar envolvidos também os trabalhadores produtivos para, no limite, acabar com a separação, advinda da administração racional, entre o planejamento e a execução de qualquer trabalho (Laurell \& Noriega, 1989; Sato, 1999).

Conforme aponta Dejours (1987), trabalho prazeroso é aquele em que cabe ao trabalhador uma parte importante da concepção. Assim, a inventividade, a criatividade, a capacidade de solucionar problemas, o emprego da inteligência é o que deve ser buscado, e é disso que fala De Masi (1999) quando estuda as principais experiências criativas de trabalho entre meados do século XIX e do século XX, tanto em empresas, como em instituições de pesquisa.
Se sob o taylorismo os indicadores mais diretos da nocividade e da exploração do trabalho estavam relacionados aos acidentes típicos e às chamadas doenças ocupacionais, características dos efeitos das matérias e dos agentes de risco existentes nos ambientes de trabalho onde ocorria a transformação industrial, também a eles associava-se uma maneira de compreender os tais agravos à saúde. Para a Medicina Legal e a Higiene do Trabalho e Industrial, os riscos ocupacionais eram vistos como infortúnios do trabalho: noção que aliava a fatalidade a uma certa suscetibilidade individual para a ocorrência de tais problemas (Barreto, 1929; Bertolli, 1992/93; Mendes, 1995).

A própria Medicina do Trabalho e depois a Saúde Ocupacional caminharam nessa trilha, ao vincularem, de modo redutor, sua visão sobre a forma de adoecer e morrer em conseqüência do trabalho aos agentes patogênicos de natureza física, química e biológica dos ambientes de trabalho onde o trabalhador/ hospedeiro com eles interage (Mendes, 1980). Com isso, o perfil de adoecimento encontrava-se circunscrito às doenças e acidentes ocupacionais puros, isto é, não se concebia que os trabalhadores adoecessem e morressem de maneira semelhante com o que ocorre com a população geral e, também, em conseqüência da inserção em processos de trabalho que se modificam historicamente dentro do mesmo modo de produção. Assim, essas modificações determinam formas de adoecimento e morte que devem ser analisadas do ponto de vista histórico para que se apreenda como as transformações do trabalho atuam na saúde/doença (Dias, 1994). É a introdução da categoria processo de trabalho, como elemento explicativo central na análise das relações entre trabalho e processo saúde/doença, a grande contribuição e ruptura epistemológica que fazem a Medicina Social Latino-Americana (Laurell, 1991) e a Saúde Coletiva (Lacaz, 1996).

Sob o fordismo, o grau de automação que vai sendo imposto ao trabalho, associado a mudanças importantes na forma de organização da jornada, como o regime de turnos alternantes, produz uma mudança no perfil da morbi-mortalidade, que associa-se, no final dos anos 60, ao aumento do absenteísmo, da insatisfação no trabalho, das operações tartaruga como maneiras de resistência ao controle fordista. São sinais do esgotamento desta forma de gestão, divisão e organização do trabalho (Frederico, 1979; Humphrey, 1982). 
A cada vez mais clara percepção do esgotamento de um ciclo coloca ao capital a necessidade de pensar em novas formas de gestão, divisão e organização do trabalho, o que começa a acontecer na década de 1970, inicialmente em países do capitalismo central, inspirados no modelo japonês. Esse modelo vai constituir-se no novo paradigma, que reacende a discussão sobre o controle e o disciplinamento dos trabalhadores. E, ressalte-se, é na organização do trabalho, que implica a divisão de tarefas e delimitação das relações sociais de trabalho, que se deve buscar as restrições para a livre manifestação da saúde mental. Ocorre que, entre nós, quando o assunto é a busca do padrão japonês de produção como paradigma de flexibilização produtiva e inovação na organização do trabalho, que seria acompanhado do fim da divisão do trabalho baseada no taylorismo e no relacionamento autoritário na empresa, existem importantes controvérsias. Essa transição/reestruturação produtiva, que engloba a questão da qualidade, tem sido conceituada como um processo que busca compatibilizar uma série de mudanças organizacionais nas relações de trabatho, implicando uma nova definição de papéis das nações e entidades do sistema financeiro, para garantir a competitividade e a lucratividade nas quais as novas tecnologias têm um papel central (Corrêa, 1997). Isso tudo começa no final dos anos 60 e início dos 70, quando evidenciam-se os limites do regime de acumulação baseado no taylorismo/fordismo, até então hegemônicos, como forma de organização do trabalho (Corrêa, 1997). O componente relativo à organização e divisão do trabalho é o lugar dos principais elementos que caracterizam a reestruturação produtiva que traz conseqüências para a vida em sociedade. Junto, aparecem subprodutos, ou seja, o desemprego, a ampliação do trabalho parcial; o trabalho de crianças e adolescentes, das mulheres e as questões de gênero correlatas, bem como a precariedade das relações de trabalho e dos direitos trabalhistas (Antunes, 1995; Brito, 1997; Gomez e Meirelles, 1997).

É mister ainda ressaltar que com o aprofundamento da automação e o avanço das novas tecnologias de informática, que passam a definir os níveis da produção a serem alcançados, houve uma clara sofisticação do disciplinamento que veio acompanhada de uma dissimulação do controle, sob o manto da idéia da qualidade e da competitividade. Tais mu- danças na organização do trabalho levam ao abandono relativo as idéias de tarefas e postos de trabalho, tão caros da organização taylorista/fordista. Daí decorrem os modos de polivalência, a articulação das atividades de operação e o controle de qualidade e manutenção (Salerno, 1994).

No Brasil tal estratégia, também uma resposta à atuação do movimento novo sindicalismo, já mencionado, parece assumir um caráter ambíguo: maior delegação de poderes acoplada à dissimulação do controle, representada, por exemplo, pelos Círculos de Controle de Qualidade/CCQs (Humphrey, 1982; Lacaz, 1983). Isso ocorre à medida em que o país passa a se inserir cada vez mais e rapidamente no mercado internacional, conjuntura em que a competitividade está a exigir tais mudanças, visando à melhoria da qualidade do que é produzido. Acontece, porém, que a Gestão Participativa e os CCQs são uma certa forma de implementá-la e, quando se dá por... iniciativa patronal é episódica e reversível (...) ocorrendo concomitantemente à intensificação forçada da mão de obra e da precarização (sic.) dos contratos (Cattani, 1997).

Não por acaso, no Brasil, a possibilidade de organização dos trabalhadores nos locais de trabalho, que deveria ser um dos pilares da busca pela qualidade do trabalho, é uma realidade muito pouco encontrada, quando não considerada indesejável ou até ilegal, dada a histórica repulsa do patronato às manifestações de independência e autonomia das classes trabalhadoras (Rodrigues, 1995).

A organização nos locais de trabalho deveria ser elemento norteador das relações de trabalho, em vista da introdução de novas tecnologias e da automação cada vez mais intensa que se observa nos setores produtivos mais modernos. Assim, é inadmissível falar em qualidade do produto sem tocar na qualidade dos ambientes e condições de trabalho, o que seria sobremaneira auxiliado pela democratização das relações sociais nos locais de trabalho.

$\mathrm{Na}$ falta dos elementos acima apontados, pode-se afirmar que esta nova empresa incorpora exigências com relações contraditórias no que se refere à saúde, tais como: maior intensidade do ritmo, maior controle e conhecimento do trabalho; polivalência e criatividade; maior liberdade de ação, reconhecimento maior do trabalho e critérios rígidos de avaliação.

Tais relações expressam-se num quadro variado de queixas no qual prevalecem o mal- 
estar difuso, como dores de cabeça e nas costas, dificuldade de dormir e cansaço que não melhora com o descanso (Monteiro, 1995).

Os estudos realizados sobre as formas de gestão participativa no Brasil, apontam para uma alienação maximizada na medida que se exige além do trabalho, a afetividade e/ou até o inconsciente (Heloani, 1994). E, quando se trata da análise da participação dos trabalhadores versus poder, observa-se que ela é apenas consultiva e que o poder de decisão não pertence a eles, particularmente em questões cruciais como no caso de demissões, por exemplo (Monteiro, 1995).

Do ponto de vista sanitário, essa realidade contraditória traz consigo um novo perfil de morbi-mortalidade dos trabalhadores. Além das doenças e acidentes associados à organização taylorista/fordista, hoje agrega-se a tendência de mudança deste perfil em que predominam doenças não reconhecidas como do trabalho, na medida que a organização (japonesa) do trabalho é o novo paradigma mundial e dele fazem parte a informática, a automação, a polivalência, a restrição hierárquica, o enxugamento do efetivo (downsizing), o desemprego etc. (Antunes, 1995).

Se, de um lado, a reestruturação exige o surgimento de um trabalhador participativo, escolarizado e polivalente, esta polivalência é vivenciada de forma ambígua, ou seja, como aumento de responsabilidade, maior carga de trabalho e menor autonomia (Monteiro, 1995).

A propósito disso, estudo recente realizado na indústria de papel e celulose gaúcha, corrobora o que foi dito, tendo mostrado que o trabalho exigia forçar a vista, ao lado de obrigar que se trabalhasse em grande velocidade, posição incômoda, o que era acompanhado de forte pressão da chefia. Essa realidade de trabalho predispunha à irritação/nervosismo, dor nas costas, dor de cabeça e cansaço - mais prevalentes no setor administrativo que, mesmo tendo melhores condições e ambientes de trabalho, apresentava cargas mais freqüentes derivadas da forma de organização e divisão do trabalho (Fassa e Facchini, 1995).

Em realidades históricas de capitalismo dependente, tal quadro associa-se à chamada precariedade do trabalho, em que o vínculo temporário e a subcontratação promovem uma perda do poder de barganha dos trabalhadores, com repercussões sobre a capacidade de negociação das condições de trabalho nos contratos coletivos (Lacaz, 1996). Tal situação, no cotidiano, obriga a realização de tarefas para as quais não houve treinamento adequado, em horários prolongados e os mais variáveis, com ritmo acelerado (Monteiro, 1995).

Em busca da meta modernizar ou perecer, fala-se em implemento da produtividade, a qual não se dá pelo aumento da produção por trabalhador, em conseqüência de mudanças tecnológicas, mas sim pela intensificação do trabalho reorganizado. É o que acontece, por exemplo, nas empresas que modernizam a tecnologia de certos momentos produtivos e terceirizam outros, o que provoca a perda de postos de trabalho, estratégia esta muito comum em empresas montadoras (Villegas et al., 1997). A esse respeito é valioso atentar para editorial do jornal Folha de S. Paulo, na edição do dia 14/11/1993, cujo sugestivo título era Produtividade e Miséria e que analisava as estatísticas divulgadas pelo Instituto Brasileiro de Geografia e Estatísticas (IBGE) sobre o aumento da produtividade industrial em meio à redução do emprego. O texto assinalava que junto ao impressionante aumento da produtividade no complexo metal-mecânico e eletrônico de cerca de 40\%, nos primeiros sete meses de 1993 e de $23 \%$ no período entre 1991 e1993 o que seria mais um recorde mundial, houve redução de 10\% no nível de emprego, considerando-se o mesmo período. Esse exército de desempregados, que demanda serviços de saúde, assistência social em função de seu baixo consumo, de insegurança social, constitui a outra face da propalada qualidade e competitividade modernizadora.

Em países periféricos, a coexistência de processos de trabalho arcaicos e modernos explica a ocorrência de um perfil híbrido, no qual os nexos de causalidade com o trabalho tornam-se mais complexos e onde nexos anteriormente não cogitados ou desvalorizados devem ser (re)colocados em pauta.

Nesse panorama sobrevêm tanto uma 'subcarga' qualitativa como uma sobrecarga quantitativa psíquica, podendo ser prognosticada a permanência da heterogeneidade tecnológica, mas com certa homogeneidade desfavorável das condições de trabalho e de vida (Laurell, 1991).

Diante disso, um novo perfil patológico configura-se, o qual é caracterizado pela maior prevalência, na população trabalhadora, de agravos à saúde marcados pelas doenças crônicas, cujo nexo de causalidade com o trabalho não é mais evidente como ocorria com as do- 
enças (e acidentes) classicamente a ele relacionadas, os chamados infortúnios do trabalho. Proliferam então as doenças cardiocirculatórias, gastrocólicas, psicossomáticas, os cânceres, a morbidade músculo-esquelética expressa nas lesões por esforços repetitivos (LERs), às quais somam-se o desgaste mental e físico patológicos e mesmo as mortes por excesso de trabalho, além das doenças psicoafetivas e neurológicas ligadas ao estresse (Gorender, 1997). Seriam, então, tais agravos os indicadores mais apropriados, nos dias que correm, para expressar o grau em que as condições, ambientes e organização do trabalho realmente se enquadram nos padrões de qualidade do trabalho que incorporam os parâmetros aqui defendidos?

Assim, no bojo desse quadro, a morbi-mortalidade tendencial da população trabalhadora aponta para uma prevalência cada vez mais freqüente de agravos caracterizados por um mal estar difuso (Seligmann-Silva, 1997) e por doenças que ocorrem na população geral, mas que entre os trabalhadores passam a ocorrer em faixa etária mais precoce, quando comparada com a população geral. O quadro 2 demonstra como tal tendência se configura de maneira bastante clara.

No quadro observa-se uma predominância das mortes por doenças cardiovasculares, que podem se relacionar à baixa autonomia de decisões no trabalho, às atividades pouco criativas e pequeno apoio social (Marmot \& Theorell, 1988); ao que se soma as mortes por causas externas, relacionadas à violência dos centros urbanos, muitas delas como resultado dos acidentes de trajeto ou do trabalho (de trânsito) dos condutores de ônibus e veículos de carga (Lucca \& Mendes, 1993) e pelos cânceres relacionados ao uso de substâncias químicas cada vez mais tóxicas (Mendes, 1988b).

Ademais, qualquer análise sobre as principais causas de aposentadoria por invalidez previdenciária durante a década de 1980, conforme mostrado a seguir (Quadro 3), também obriga a pensar na participação do trabalho como determinante desta morbidade, particularmente no que se refere à hipertensão arterial, transtornos mentais e doenças osteoarticulares (Mendes, 1988a).

\section{Conclusão}

Pode-se afirmar que a temática da QVT assume maior relevância nos anos 70, quando se dá um esgotamento da organização do trabalho de corte taylorista/fordista, ao qual associa-se um aumento do absenteísmo, da insatisfação no trabalho e da não aderência dos trabalhadores às metas definidas pela gerência. O modelo japonês é o novo paradigma de

\section{Quadro 2}

Principais causas de óbito no grupo etário de 20 a 49 anos, nas maiores cidades da região do ABC paulista, na década de 1980.

\begin{tabular}{|c|c|c|c|c|}
\hline \multicolumn{5}{|l|}{ Santo André } \\
\hline Tumores malignos & Homicídios & $\begin{array}{l}\text { Lesões traumáticas } \\
\text { e envenenamentos }\end{array}$ & $\begin{array}{l}\text { Acidentes com } \\
\text { veículos a motor }\end{array}$ & $\begin{array}{l}\text { Doenças isquêmicas do } \\
\text { coração e cerebrovasculares }\end{array}$ \\
\hline \multicolumn{5}{|l|}{ São Caetano do Sul } \\
\hline Tumores malignos & $\begin{array}{l}\text { Lesões traumáticas } \\
\text { e envenenamentos }\end{array}$ & $\begin{array}{l}\text { Doenças isquêmicas do } \\
\text { coração e cerebrovasculares }\end{array}$ & $\begin{array}{l}\text { Acidentes com } \\
\text { veículos a motor }\end{array}$ & Homicídios \\
\hline \multicolumn{5}{|c|}{ São Bernardo do Campo } \\
\hline Homicídios & Tumores malignos & $\begin{array}{l}\text { Lesões traumáticas } \\
\text { e envenenamentos }\end{array}$ & $\begin{array}{l}\text { Acidentes com } \\
\text { veículos a motor }\end{array}$ & $\begin{array}{l}\text { Doenças cerebrovasculares } \\
\text { e isquêmicas do coração }\end{array}$ \\
\hline \multicolumn{5}{|l|}{ Diadema } \\
\hline Homicídios & $\begin{array}{l}\text { Lesões traumáticas } \\
\text { e envenenamentos }\end{array}$ & $\begin{array}{l}\text { Sintomas e } \\
\text { sinais maldefinidos }\end{array}$ & $\begin{array}{l}\text { Doenças } \\
\text { cerebrovasculares }\end{array}$ & $\begin{array}{l}\text { Acidentes com } \\
\text { veículos a motor }\end{array}$ \\
\hline
\end{tabular}

Fonte: Departamento/Escritório Regional de Saúde de Santo André, SP. Secretaria de Estado da Saúde. 
organização do trabalho, visando superar essa realidade, apesar de tal modelo, conforme apontam alguns estudiosos, reduzir a autonomia nas relações de trabalho, além de envolver um controle importante da vida extraprofissional pela estrita utilização do tempo a serviço da empresa (Antunes, 1995; Hirata e Zarifian, 1991).

Mesmo diante dos vários enfoques que vai assumindo a QVT, interessou aqui ressaltar que para a OIT, a temática é expressada no PIACT, lançado em 1976, procurando articular duas vertentes: uma relacionada à melhoria da qualidade geral de vida como aspiração humana e que não poderia ser barrada no portão das fábricas; e outra relativa à maior participação dos trabalhadores nas decisões que dizem respeito à sua vida e atividade de trabalho. Nesse sentido, a saúde e a qualidade do trabalho não podem ser negociadas como mais um mero elemento da produção. Tal abordagem visava superar a prevenção dos acidentes e doenças considerados diretamente ligados ao trabalho, priorizando a busca de outros nexos saúde-trabalho, para além da causalidade direta. Os agravos à saúde, que também ocorrem na população geral, quando relacionados ao trabalho assumem um perfil diferenciado.

A Organização Mundial da Saúde, no ano de 1979, advogou a estratégia da necessidade de desenvolver-se programas especiais de atenção à saúde dos trabalhadores, visando promover melhorias nas condições da qualidade de vida e trabalho nos países em desenvolvimento (Freitas et al., 1985).

Ressalte-se que a idéia de QVT aqui defendida envolve questões intrinsecamente ligadas às novas tecnologias e seu impacto para a saúde e o meio ambiente; aos salários, incentivos e participação nos lucros das empresas; à criatividade, autonomia, grau de controle e quantidade de poder dos trabalhadores sobre o processo de trabalho (Laurell e Noriega, 1989).

\section{Quadro 3}

Causas de aposentadoria por invalidez previdenciária no Brasil, na década de 1980

\section{Causa invalidante}

Hipertensão arterial

Transtornos mentais

Doenças osteoarticulares

Doenças cardiovasculares

Epilepsias

Doenças infectocontagiosas

Fonte: Coordenadoria de Informática da Secretaria de Planejamento do Instituto Nacional de Previdência Social/INPS.

Disso decorre que se defenda a conquista de um (re)planejamento do trabalho em que a gestão participativa seja real, com verdadeiros canais coletivos de negociação - capital-trabalho, visando à resolução dos conflitos/contradições de interesses e a superação de uma certa gestão participativa de caráter patronal, episódica e reversível, porque acompanhada da intensificação, da precariedade do trabalho e dos contratos e direitos trabalhistas (Antunes, 1995).

Urge, portanto, um debate que tenha como foco a possibilidade de organização a partir dos locais de trabalho, de forma a possibilitar uma discussão das demandas de maneira democrática e igualitária, visando submeter as questões ligadas à competitividade/produtividade e qualidade do produto à qualidade do trabalho e à defesa da vida e da saúde no trabalho. Daí ser necessária a utilização de outros indicadores sanitários que melhor espelhem as maneiras atuais de consumo da força de trabalho, acopladas à reengenharia produtiva em que prevalece a entrada de novos e desconhecidos insumos quanto à nocividade à saúde e ao ambiente, aliada ao aprofundamento da automação e informatização $\mathrm{n}(\mathrm{d})$ o processo produtivo. 


\section{Referências bibliográficas}

Antunes RC 1995. Adeus ao trabalho?: Ensaio Sobre as Metamorfoses e a Centralidade do Mundo do TrabaTho. Cortez Editora-Editora Unicamp, São PauloCampinas, SP. 155 pp.

Barreto JB 1929. Prevenção de acidentes de trabalho. Archivos de Hygiene 2:342-364.

Berlinguer G 1993. A relação entre saúde e trabalho do ponto de vista bioético. Saúde e Sociedade 2(2):101134.

Bertolli Filho C 1992/93. Medicina e trabalho: As "ciências do comportamento" na década de 40. Revista de História 127/128:37-51.

Brito J 1997. Uma proposta de vigilância em saúde do trabalhador com a ótica de gênero. Cadernos de $\mathrm{Sa}$ úde Pública 13(2):141-14.

Cattani AD 1997. Ação sindical em face da automação, pp. 21-25. Autonomia, pp. 27-34. Gestão participativa, pp. 107-114. AD Cattani (org.). Trabalho e Tecnologia: Dicionário Crítico. Ed. Vozes-Ed. Universidade, Petrópolis-Porto Alegre.

Ciborra C \& Lanzara GF (orgs.) 1985. Progettazione delle Tecnologie e Qualita del Lavoro. Franco Angeli Editore, Milão. 330 pp.

Corrêa MB 1997. Reestruturação produtiva e industrial. AD Cattani (org.). Trabalho e Tecnologia: Dicionário Crítico. Ed. Vozes-Ed. Universidade, Petrópolis-Porto Alegre. pp. 202-205.

Dejours C 1987. A Loucura do Trabalho: Estudo de Psicopatologia do Trabalho. Ed. Oboré, São Paulo. 163 pp.

Dias EC 1994. A Atenção à Saúde dos Trabalhadores no Setor Saúde (SUS), no Brasil: Realidade, Fantasia ou Utopia? Tese de doutorado. Faculdade de Ciências Médicas, Universidade Estadual de Campinas, Campinas. $324 \mathrm{pp}$.

De Masi D (org.) 1999. A Emoção e a Regra: os Grupos Criativos na Europa de 1850 a 1950. José Olympio, Rio de Janeiro. 419 pp.

Fassa A e Facchini LA 1995. Trabalho e saúde em indústria de celulose e papel: perfil segundo setor, p. 115 III Congresso Brasileiro de Epidemiologia, Salvador.

Fleury ACC e Vargas N (coords.) 1983. Organização do Trabalho: uma Abordagem Interdisciplinar. Atlas, São Paulo. 232 pp.

Folha de S. Paulo (Editorial). Produtividade e miséria, pp.1-2, edição de 14/11/1993.

Foucault M 1994. Vigiar e Punir: Nascimento da Prisão. Ed. Vozes, Petrópolis. 277 pp.

Frederico C 1979. Consciência Operária no Brasil. (Estudo de um Grupo de Trabalhadores). Ática, São Paulo. 140 pp.

Freitas CU, Lacaz FAC e Rocha LE 1985. Saúde pública e ações de saúde do trabalhador: uma análise conceitual e perspectivas de operacionalização programática na rede básica da Secretaria de Estado da Saúde. Temas IMESC, Sociedade, Direito, Saúde 2(1):3-10.

Gardell B 1982. Scandinavian research on stress in working life. International Journal of Health Services 12(1):31-41.

Gomez MC e Meirelles ZV 1997. Crianças e adolescentes trabalhadores: um compromisso para a saúde coletiva. Cadernos de Saúde Pública 13(2):135-140.
Gorender J 1997. Globalização, tecnologia e relações de trabalho. Estudos Avançados 29(11):311-361.

Heloani JR 1994. Organização do Trabalho e Administração: uma Visão Multidisciplinar. Ed. Cortez, São Paulo. $112 \mathrm{pp}$.

Hirata H e Zarifian P 1991. Força e fragilidade do modelo japonês. Estudos Avançados 12(5):173-184.

Humphrey J 1982. Fazendo o "Milagre": Controle Capitalista e Luta Operária na Indústria Automobilística Brasileira. Ed. Vozes/CEBRAP, Petrópolis. 251 pp.

Karasek R 1979. Job demands, job decision latitude and mental strain: implications for job design. Administrative Science Quarterly 24:285-308.

Karasek R et al. 1981. Job decision latitude, job demands and cardiovascular disease: a prospective study of Swedish men. American Journal of Public Health 71(7):694-705.

Lacaz FAC 1983. Saúde no Trabalho. Dissertação de mestrado. Departamento de Medicina Preventiva, Faculdade de Medicina, USP, São Paulo. 147 pp.

Lacaz FAC 1996. Saúde do Trabalhador: um Estudo sobre as Formações Discursivas da Academia, dos Serviços e do Movimento sindical. Tese de doutorado. Departamento de Medicina Preventiva e Social, Faculdade de Ciências Médicas, Unicamp, Campinas. 435 pp.

Laurell AC 1991. Trabajo y salud: estado del conocimiento, pp. 249-339. In S Franco, ED Nunes, J Breilh e AC Laurell (orgs.). In Debates en Medicina Social. (Serie Desarollo de Recursos Humanos, n. 92) pp. 249-339. OPAS-ALAMES, Quito.

Laurell AC e Noriega M 1989. Processo de Produção e Saúde. Trabalho e Desgaste Operário. CEBES-HUCITEC, São Paulo. 333 pp.

Lucca SR e Mendes R 1993. Epidemiologia dos acidentes do trabalho fatais em área metropolitana da região sudeste do Brasil, 1979-1989. Revista de Saúde Pública 27(3):168-176.

Marmot M e Theorell T 1988. Social class and cardiovascular disease: the contribution of work. International Journal of Health Services 18(4):659-674.

Mendes R (org.) 1980. Medicina do Trabalho-Doenças Profissionais. Sarvier, São Paulo. 573 pp.

Mendes R 1988. Subsídios para um debate em torno da revisão atual do modelo de organização da saúde ocupacional no Brasil. Revista Brasileira de Saúde Ocupacional 16(64):7-25.

Mendes R 1988a. Impacto dos efeitos da ocupação sobre a saúde dos trabalhadores. I. Morbidade. Revista de Saúde Pública 22:311-326.

Mendes R 1988b. Impacto dos efeitos da ocupação sobre a saúde dos trabalhadores. I. Mortalidade. Revista de Saúde Pública 22:441-457.

Mendes R (org.) 1995. Patologia do Trabalho. Atheneu, Rio de Janeiro. 625 pp.

Mendes R e Dias EC 1991. Da medicina do trabalho à saúde do trabalhador. Revista de Saúde Pública 25 (5):341-349.

Monteiro MS 1995. Gestão Participativa no Trabalho e Saúde: um Estudo de Caso. Dissertação de mestrado. Departamento de Saúde Ambiental, Faculdade de Saúde Pública, USP, São Paulo. 125 pp. 
Olsen O e Kristensen TS 1991. Impact of work environment on cardiovascular diseases in Denmark. Journal of Epidemiology and Community Health 45: 4-10.

Ortsman O 1984. Mudar o trabalho. As experiências, os métodos, as condições de experimentação social. Fundação Calouste Gulbenkian, Lisboa. 410pp.

Parmegianni L 1986. Occupational health services in 1984: a prospective model. American Journal of Industrial Medicine 7:91-92.

Rebouças AJA et al. 1989. Insalubridade-morte lenta no trabalho. DIESAT/Oboré, São Paulo. 223 pp.

Ribeiro HP e Lacaz FAC (orgs.) 1984. De que Adoecem e Morrem os Trabalhadores? IMESP/DIESAT, São Paulo. 236 pp.

Rodrigues IJ 1995. O sindicalismo brasileiro da confrontação à cooperação conflitiva. São Paulo em Perspectiva 9(3):116-126.

Rodrigues MCV 1991. Qualidade de vida no trabalho: evolução e análise no nível gerencial. Fundação Edson Queirós, Fortaleza. (Mimeo).

Salerno MS 1994. Trabalho e organização na empresa industrial integrada e flexível. C Ferretti (org.). Novas Tecnologias, Trabalho e Educação. Ed. Vozes, Petrópolis.

Sato L 1991. Abordagem Psicossocial do Trabalho Penoso: Estudo de Caso de Motoristas de Ônibus Urbano. Dis- sertação de mestrado. Programa de Estudos PósGraduados em Psicologia Social, PUC, São Paulo. 115 pp.

Sato L 1999. Qualidade de vida. 4 pp. (Mimeo).

Seligmann-Silva E 1997. Saúde mental e automação: a propósito de um estudo de caso no setor ferroviário. Cadernos de Saúde Pública 13(2):95-110.

Taylor FW 1982. Princípios de Administração Científica. Atlas, São Paulo. 134 pp.

Vezina M 1988. Work-related psychological disorders: alternative approaches. Quebec. (Mimeo).

Vieira DFVB 1993. Qualidade de Vida no Trabalho dos Enfermeiros em Hospital de Ensino. Dissertação de mestrado. Programa de Pós-Graduação em Administração. Universidade Federal do Rio Grande do Sul, Porto Alegre. 169 pp.

Villegas J, Noriega M, Martinez S, Martines S 1997. Trabajo y salud en la industria maquiladora mexicana: una tendencia dominante en el neoliberalismo dominado. Cadernos de Saúde Pública 13(2):123-34.

Wünsch Filho V 1998. Reestruturação produtiva e acidentes de trabalho no Brasil, São Paulo. 21 pp. + anexos. (Mimeo)

Zavattaro HA 1999. A Qualidade de Vida no Trabalho de Profissionais da Área de Informática: um Estudo Exploratório. Dissertação de mestrado. Instituto de Psicologia, USP, São Paulo. 